اثر آبيارى تكميلى در مراحل مختلف رشد بر عملكرد و بهرهورى آب كلزا هاييزه رقم روهان

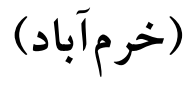

فاطمه عليزاده، على حيدر نصر الهى"، مهرى سعيدىنيا و مجيد شريفى بور'

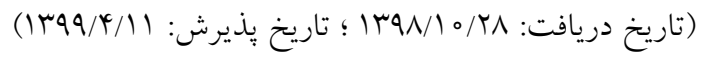

جكيده

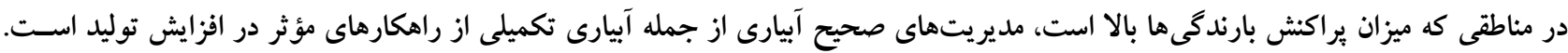

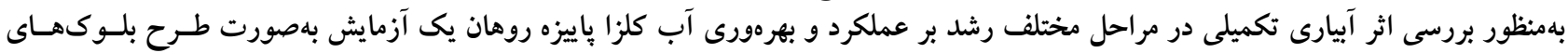

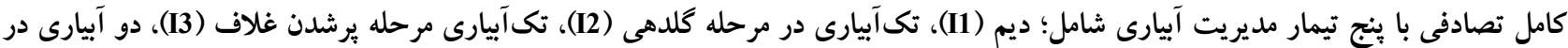

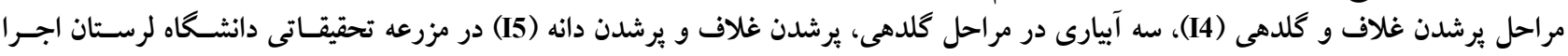

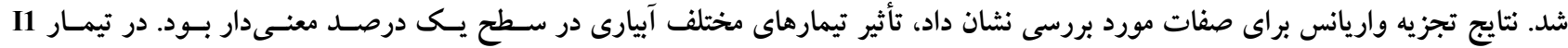

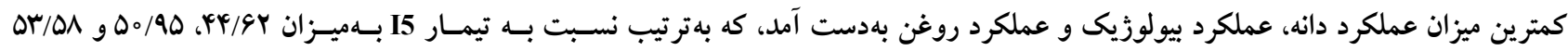

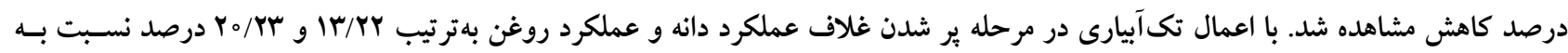

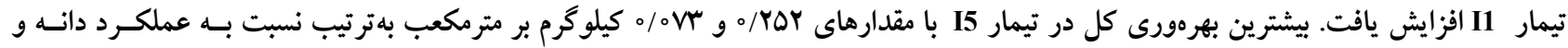

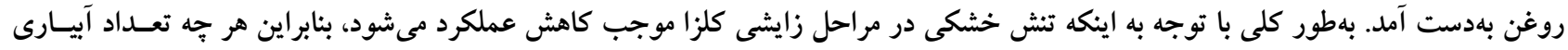

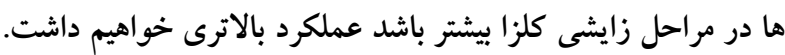

وازههاى كليدى: تكآييارى، عملكرد روغن، عملكرد بيولوزيك، تنش آبى

1. كروه مهندسى آب ، كرايش آبيارى و زهكشى، دانشكده كشاورزى و منابع طبيعى، دانشخاه لرستان

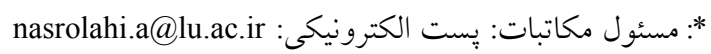


مرحله كلدهى و نيز تعداد دانه در غلاف را در اثر ايجـاد سـطح

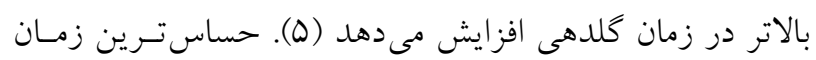

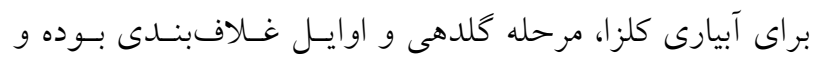

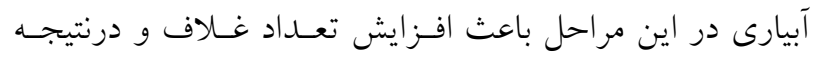
افزايش عملكرد دانه مىشـود. در تحقيقسى كـه روى اثـر تسنش

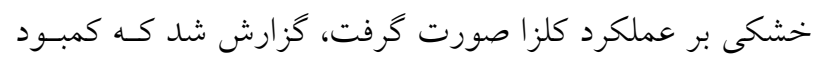

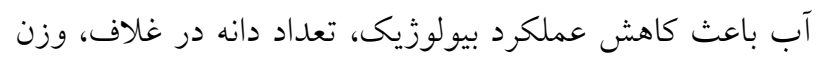
دانه درنتيجه عملكرد دانسه و روغـن مسى شـود (4 (). بـهمنظـور

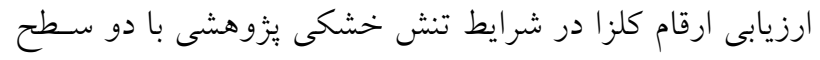

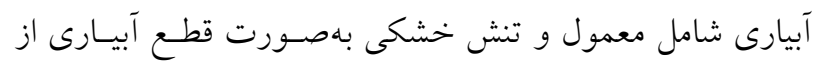

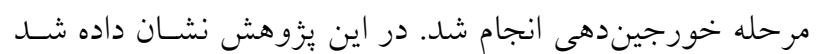

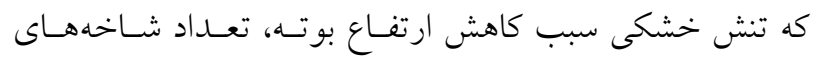
فرعى در بوته، تعداد خورجين در بوته، تعلداد دانه در خورجين،

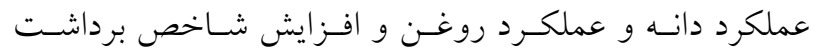

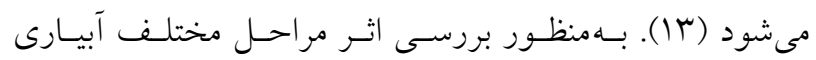

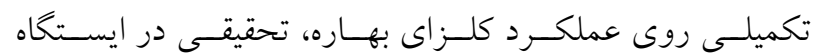

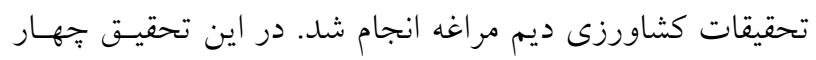

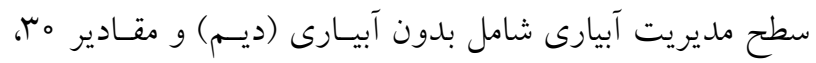

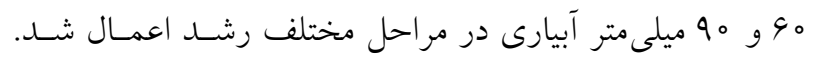

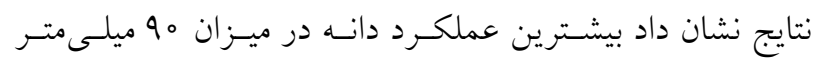

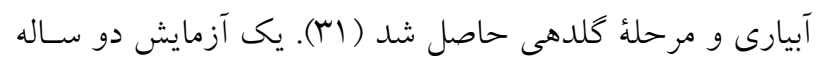
بهمنظور تعيين تأثير آبيارى تكميلى بر عملكرد و اجز إى عملكرد

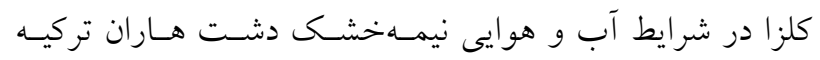

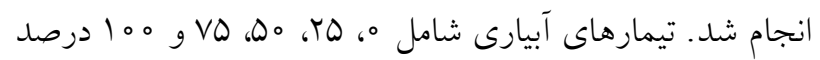

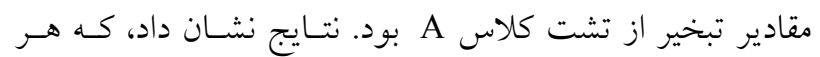

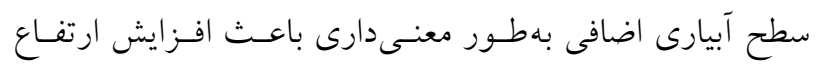

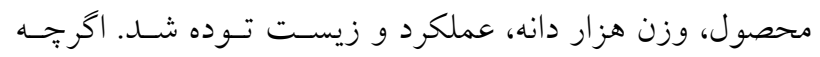

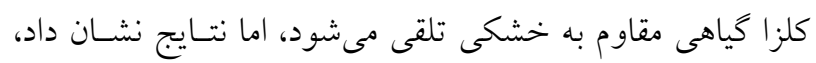

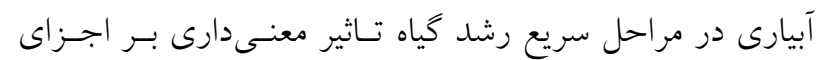

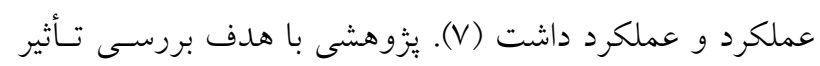

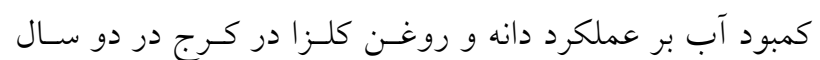

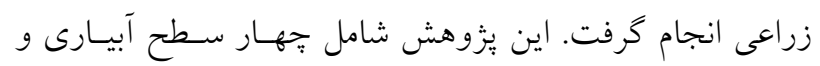

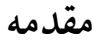

در اقليمهايى كه شامل تابستانهاى گرموخشك و زمسـتانهـاى

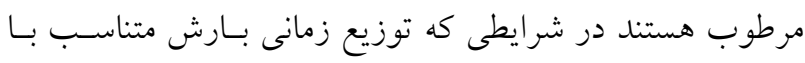

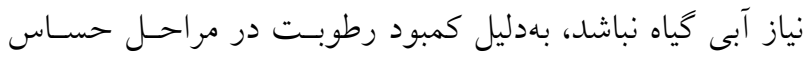

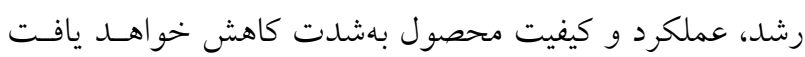

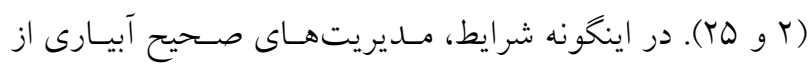

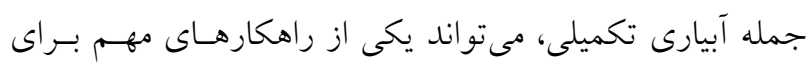

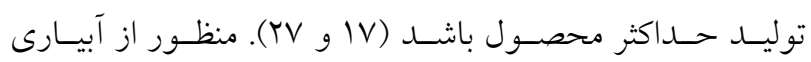

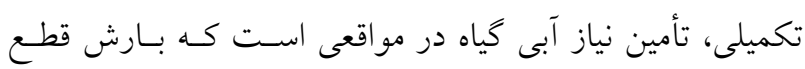

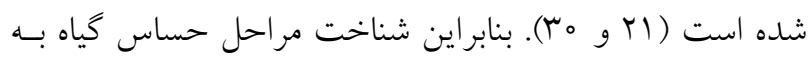

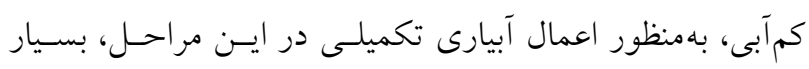

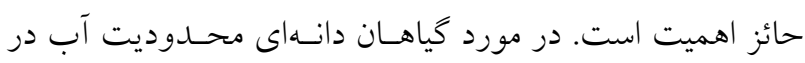
طـول دوره رشـد، كميـت و كيفيـت دانـه را تحست تـأثير قـرار

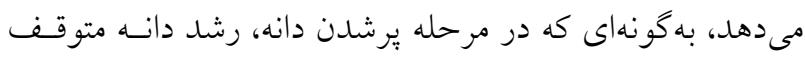

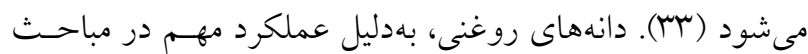
تغذيهاى، در سراسر جهان، با تقاضـاى زيـادى روبـهرو هستـند

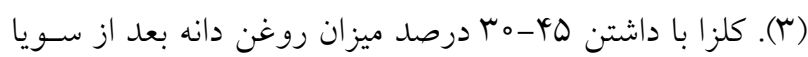

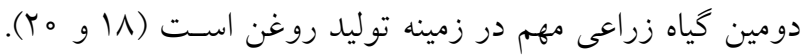

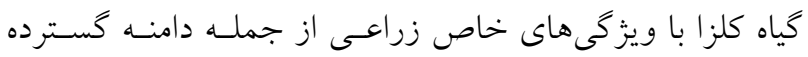

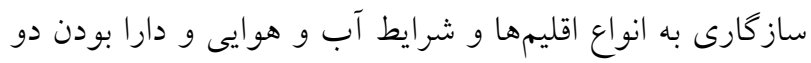

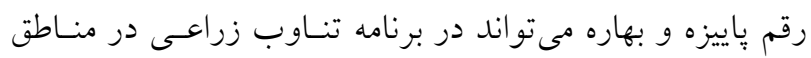

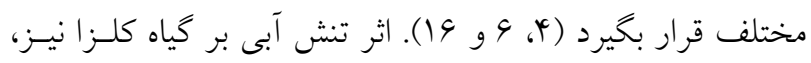

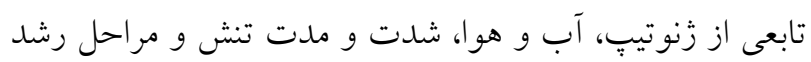

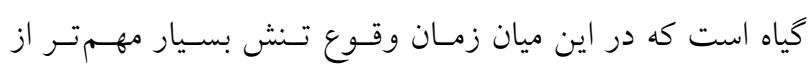

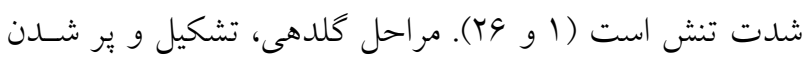

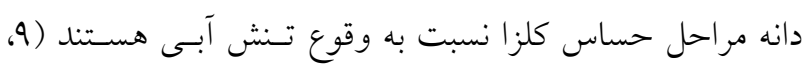

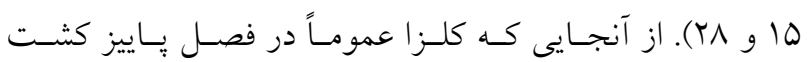

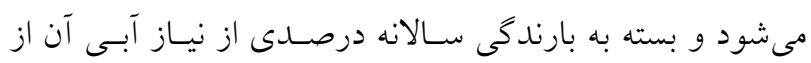

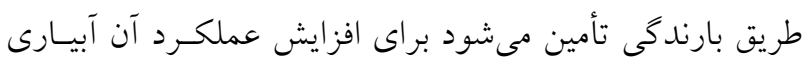

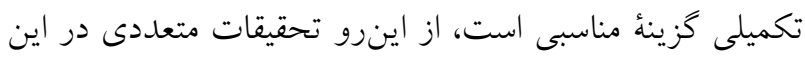

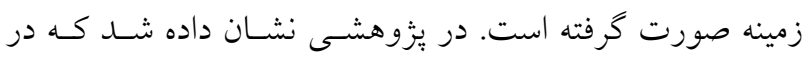

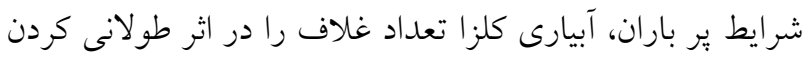


بهبود بهرهورى آب ضرورى است. لذا تحقيق حاضر به بررسى

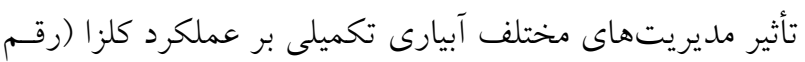

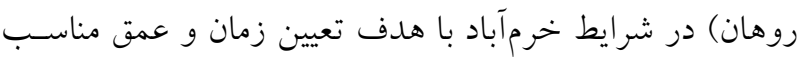
آبيارى تكميلى براى دستيابى به حداكثر عملكرد مى يردازد.

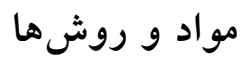

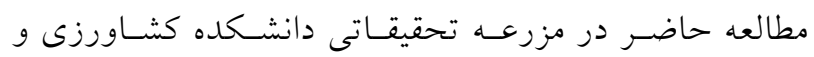

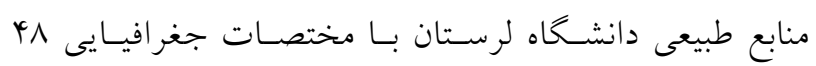
درجه و ل1 ادقيقه شرقى و سب درجسه و وب دقيقـه شـمالى و

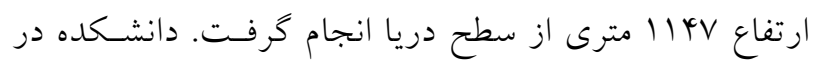

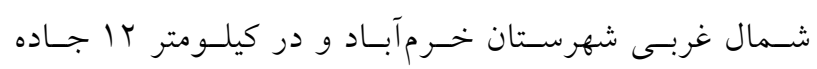

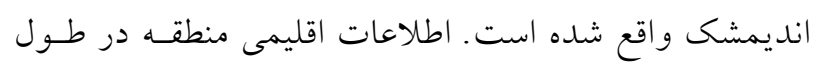

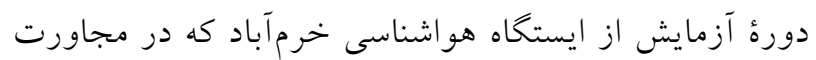

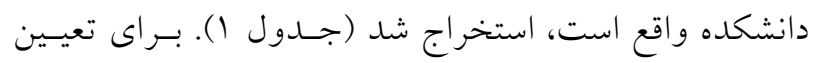

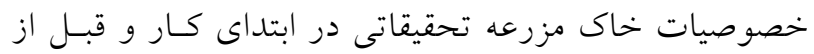

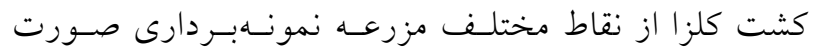

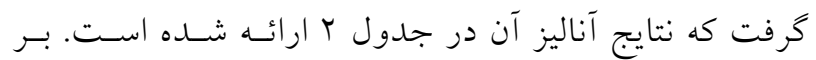

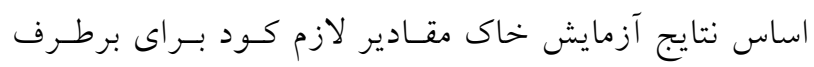

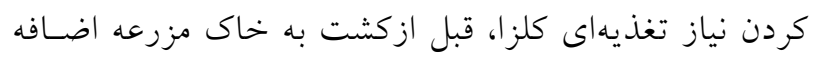

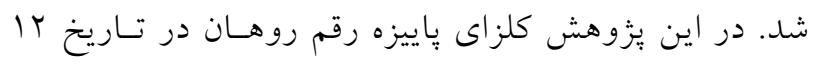

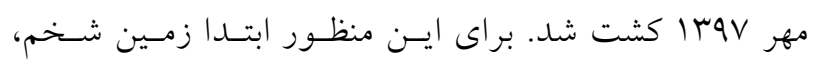

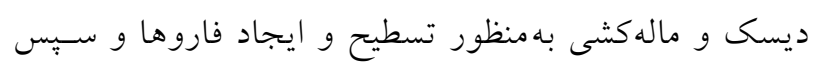

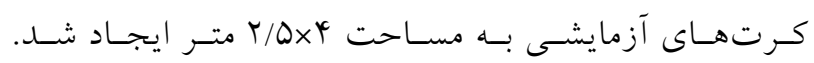

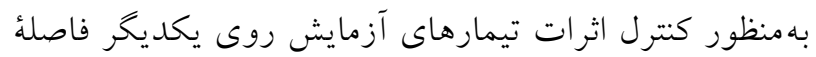

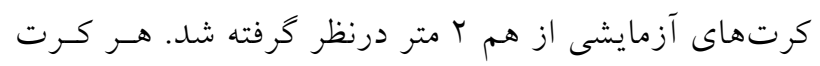

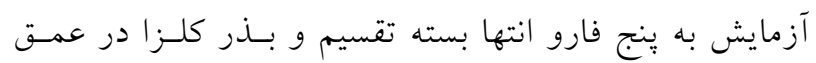

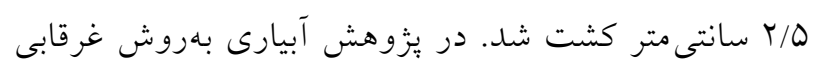

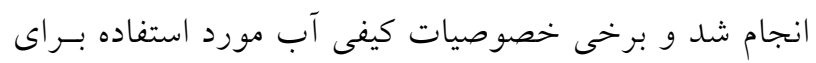

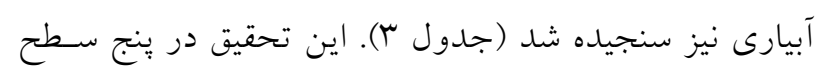

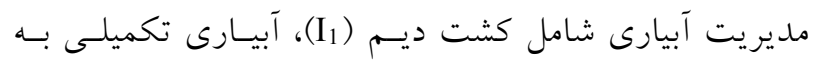

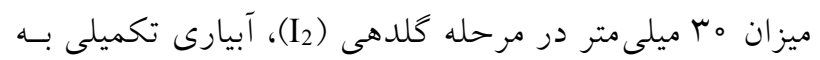

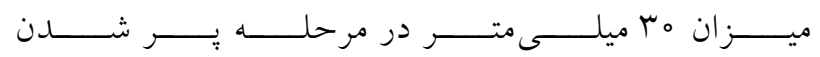

شش رقم كلزا بود. نتايج نشان داد كه بيشترين كـاهش عملكـرد

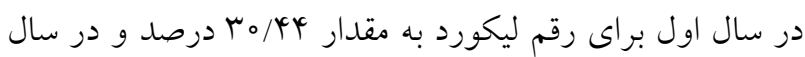

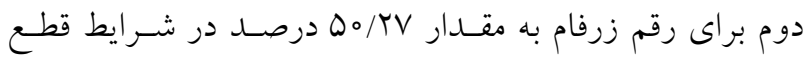

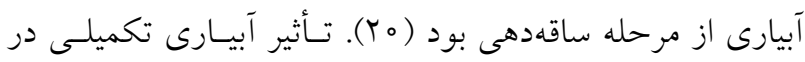

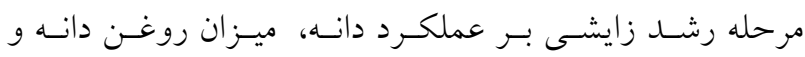

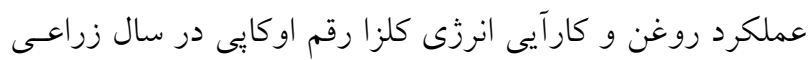
أماه تعاد

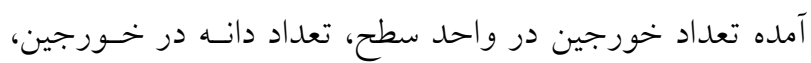

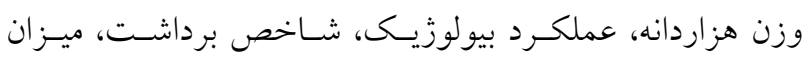

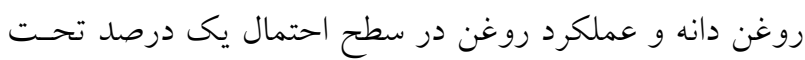

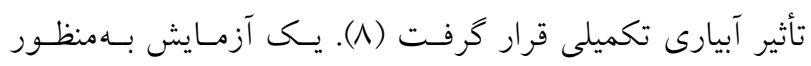

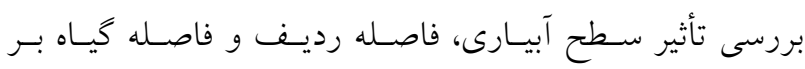

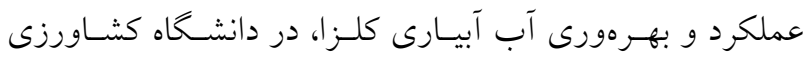

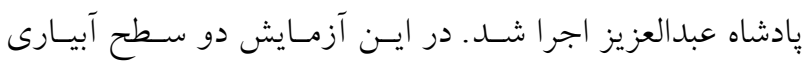

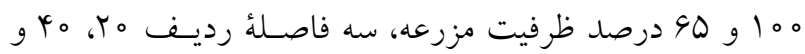

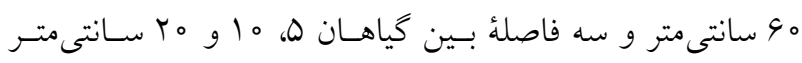
مورد بررسى قرار كرفت. نتايج نشان داد كـه سطعح آبيـارى 90

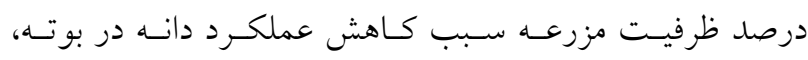

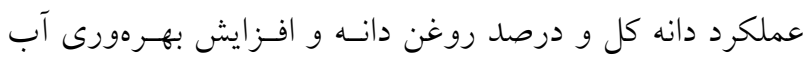

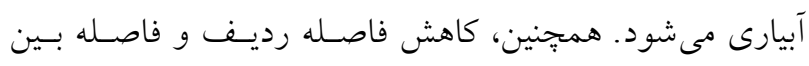

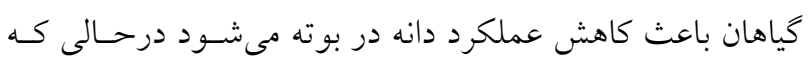

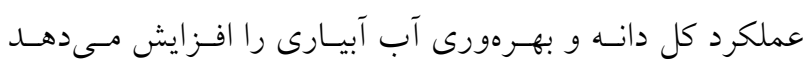

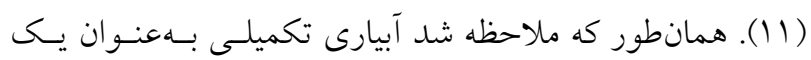

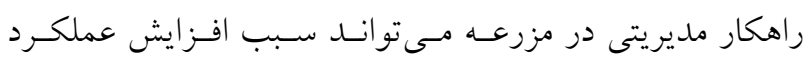

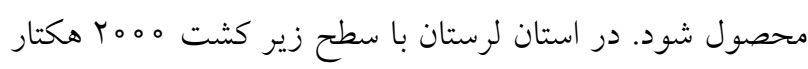

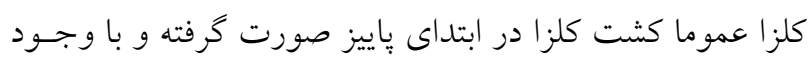

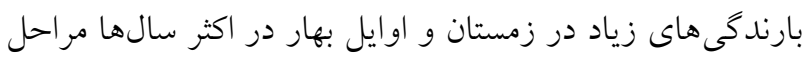

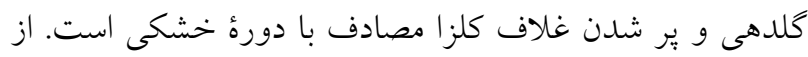

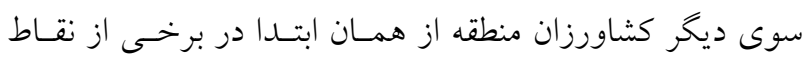

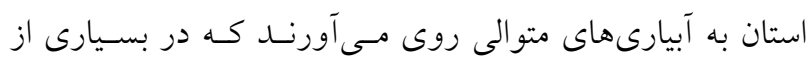

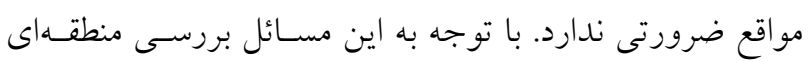

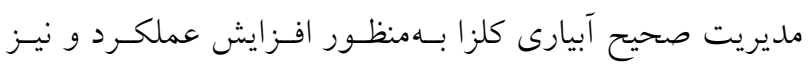


جدول ا. يارامترهاى هواشناسى منطقه در طول دوره رشد

\begin{tabular}{|c|c|c|c|c|c|c|c|c|c|}
\hline خرداد & ارديبهشت & فروردين & اسفند & بهمن & دى & آذر & 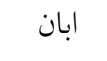 & مهر & يّار امتر هواشناسى \\
\hline TG/YT & IV/VA & $I T / T V$ & $V / \pi 9$ & $9 / 49$ & $9 / 09$ & $N / D Q$ & $1 \% / \Lambda$ & $r Y / l Q$ & ميانخين درجه حرارت (COC) \\
\hline 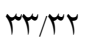 & $\Delta \Delta / V \mu$ & $99 / 40$ & $99 / 0 Y$ & $G V / M Y$ & $99 / 00$ & $V Y / T Y$ & $90 / 1 T$ & $r \circ / 90$ & ميانخين رطوبت نسبى (\%) \\
\hline$r / Y \wedge$ & $9 / 94$ & $V / 19$ & V & $0 / 4 q$ & Q/r & $\varphi / 4 V$ & $0 / 9 \mathrm{~V}$ & $\mathrm{~V} / \circ \mathrm{r}$ & ميانخين سرعت باد \\
\hline$\circ$ & $9 / 1$ & $r \circ q / 1$ & $99 / 9$ & $110 / r$ & $\mid r V / \circ r$ & $10 \circ / 1$ & $1 r q / 11$ & $9 / 04$ & مجموع بارندگى (mm) \\
\hline
\end{tabular}

جدول r. خصوصيات فيزيكى و شيميايى خاك مزرعه

\begin{tabular}{|c|c|c|c|c|c|c|c|c|c|c|}
\hline $\begin{array}{c}\text { PWP } \\
(\text { \% \% \% \% }\end{array}$ & 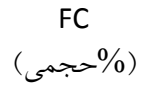 & $\begin{array}{c}\rho b \\
\left(\mathrm{gr} \mathrm{cm}^{-3}\right)\end{array}$ & $\begin{array}{c}\mathrm{K} \% \\
\left(\mathrm{mg} \mathrm{kg}^{-1}\right)\end{array}$ & $\begin{array}{c}\mathrm{P} \% \\
\left(\mathrm{mg} \mathrm{kg}^{-1}\right)\end{array}$ & $\begin{array}{c}\mathrm{N} \% \\
\left(\mathrm{mg} \mathrm{kg}^{-1}\right)\end{array}$ & $\begin{array}{c}\mathrm{OC} \\
\%\end{array}$ & 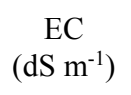 & $\mathrm{pH}$ & بافت خاك & عمق خاك \\
\hline $14 / 0$ & $r Q / \varphi$ & $1 / 1 Y$ & DYD & TY & $0 / 09$ & $0 / 9 V$ &.$/ 90$ & V/OT & لوم-رسى & o-r。 \\
\hline $\mid y / 4$ & TQ & $1 / 1 r$ & 190 & ir & $\circ / \wedge$ & $\circ / \mathrm{VA}$ & $0 / 94$ & V/VI & لوم-رسى & $\mu_{0}-\varphi_{0}$ \\
\hline
\end{tabular}

جدول r. خصوصيات كيفى آب آبيارى در طول فصل

\begin{tabular}{|c|c|c|c|c|c|c|}
\hline SAR & $\mathrm{Na}^{+}(\mathrm{meq} / \mathrm{l})$ & $\mathrm{Mg}^{2+}(\mathrm{meq} / \mathrm{l})$ & $\mathrm{Ca}^{2+}(\mathrm{meq} / \mathrm{l})$ & TDS (meq/l) & $\mathrm{EC}(\mathrm{dS} / \mathrm{m})$ & $\mathrm{PH}$ \\
\hline$\circ / \mu^{2}$ & $1 / T \Lambda$ & $1 / 9$ & $4 / 9$ & rqV & $0 / 9$ & V \\
\hline
\end{tabular}

مخصوص ظاهرى خاى (كرم بر سـانتى متـر مكعـب)، Dr: ارتفــاع

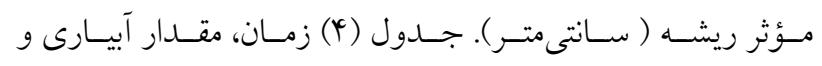
خصوصيات فنولوزيـك مربوطـه را در تيمـارهـاى مختلـف نشـان

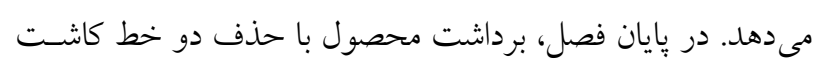

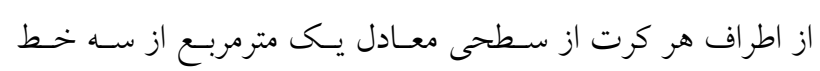
كاشت داخلى صورت گرفت و يُ از انتقال به آزمايشگاه عملكـرد بيولوزيك، عملكرد دانه، عملكرد روغن دانه، ارتفاع بوته، وزن هزار دانه، طول غلاف و درصد روغن دانه انـدازهخيـرى شـــ درنهايـت

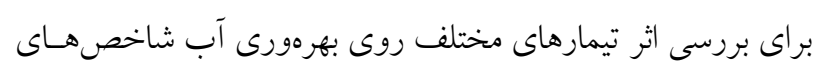

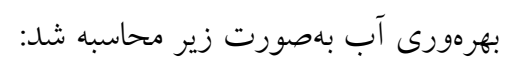
$\mathrm{WP}_{\mathrm{I}}=\mathrm{Y} / \mathrm{I}$
$\mathrm{WP}_{\mathrm{p}}=\mathrm{Y} / \mathrm{P}$

غلاف (II3)، آبيارى تكميلى به ميزان هب ميلى متر در مرحلـه يـر

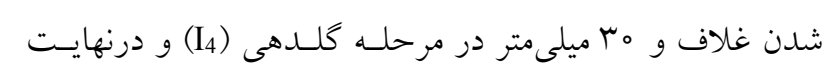

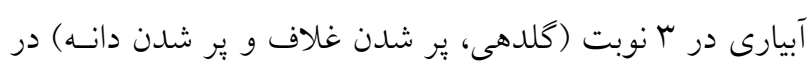

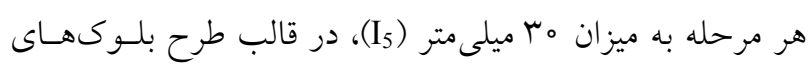
كامل تصادفى و در سه تكرار انجام شد (شكل (1). بـراى تعيسين عمق آبيارى در هر مرحله، كمبود رطوبت خاك بهعنـوان عمـق خالص و معادل ه ما درصد نياز آبى گيـاه درنظـر كرفتسه شــد.

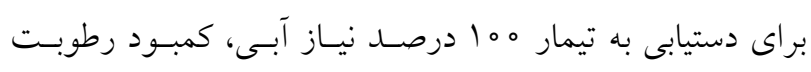
خاى در عمق ريشه كياه، با استفاده از معادله زير محاسبه شد: $\mathrm{d}_{\mathrm{n}}=\left(\theta_{\mathrm{fc}}-\theta_{\mathrm{i}}\right) \rho b . \mathrm{Dr}$

در رابطه بالا:

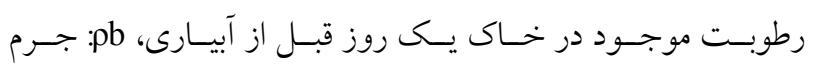



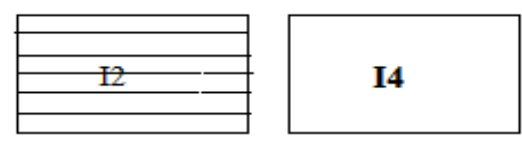

Il

13
15

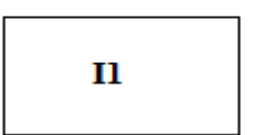

3

I2

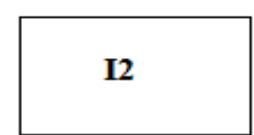

I5

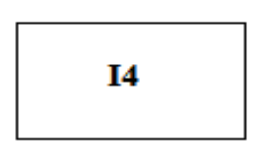

| $2 \mathrm{~m}$

13

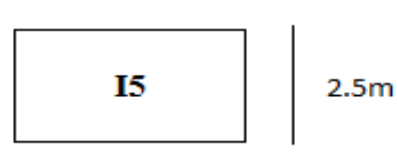

$4 \mathrm{~m}$

شكل 1. نقشه كلى طرح

جدول f. زمان، مقدار آب آبيارى و خصوصيات فنولوزيك در تيمارهاى مختلف

\begin{tabular}{|c|c|c|c|c|}
\hline خصوصيات فنولوزيك & تعداد روز بعد از كشت & تاريخ آبيارى & مقدار آب آبيارى (mm) & تيمار \\
\hline- & - & - & - & I1 \\
\hline كلدهى & ro9 & $9 \Lambda / r / \Lambda$ & $r_{\circ}$ & $\mathrm{I} 2$ \\
\hline يرشدن غلاف & TYI & QN/T/YY & $r_{\circ}$ & $\mathrm{I} 3$ \\
\hline كلدهى & r.9 & $9 \Lambda / Y / \Lambda$ & $\varepsilon_{0}$ & 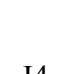 \\
\hline يرشدن غلاف & TYI & QN/T/YY & 70 & 14 \\
\hline 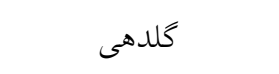 & ros & $9 N / Y / \Lambda$ & & \\
\hline يرشدن غلاف & TYI & $Q N / T / Y Y$ & 9. & I5 \\
\hline يرشدن دانه & rmq & $9 \Lambda / \Gamma / \Lambda$ & & \\
\hline
\end{tabular}

احتمـال 99 درصــــ انجــام شــــ و درنهايـت بــراى مقايســ

$\left.\mathrm{WP}_{(\mathrm{P}+\mathrm{I})}=\mathrm{Y} / \mathrm{P}+\mathrm{I}\right)$

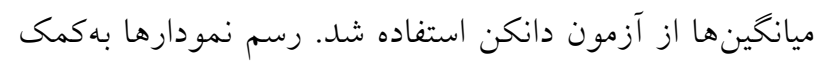

$$
\text { EXCEL }
$$

نتايج و بحث

تتايج تجزيه واريانس مديريتهـاى مختلـف آبيـارى نشـان داد

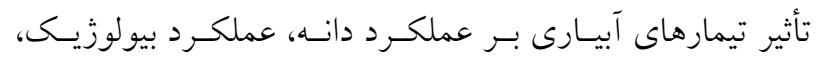

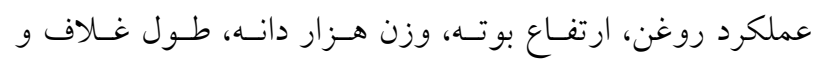

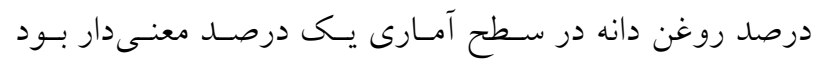

در روابط بـالا: Y عملكـــ روغـن (كيلـو كرم در هكتــار) يـا

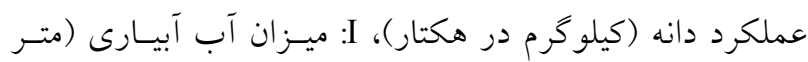

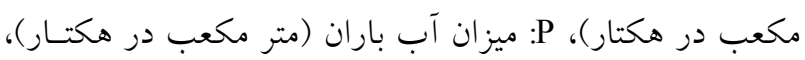

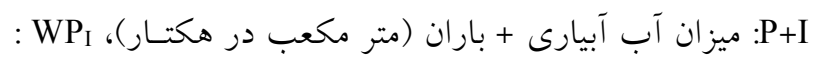
:WPp :

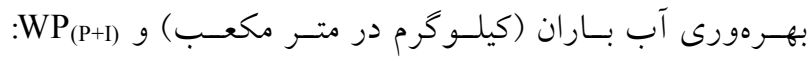
بهروورى آب كـل (كيلـو گرم در متـر مكعـب) اسـت. در ايسن

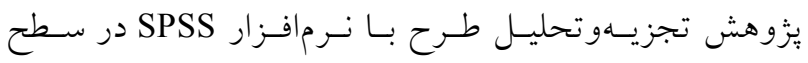


جدول ه. تجزيه واريانس تأثير تيمارهاى آبيارى بر عملكرد و اجزاى عملكرد كلزا

\begin{tabular}{|c|c|c|c|c|c|c|c|c|}
\hline \multicolumn{7}{|c|}{ ميانگين مربعات } & \multirow{3}{*}{ درجه آزادى } & \multirow[b]{2}{*}{ منابع تغييرات } \\
\hline درصد & طول & وزن هزار & ارتفاع & عملكرد & عملكرد & عملكرد & & \\
\hline روغن دانه & غلاف & دانه & بوته & روغن & بيولوزيك & دانه & & \\
\hline$\Lambda / \Lambda \mu \mu^{* *}$ & $1 / 0 \circ Y^{* *}$ & $\circ / V q^{* *}$ & $0 / Y \xi^{* *}$ & VQYTI/DG & TMY०GVVQ/MYY & GV৭OVA/VYQ *** & r & تيمار \\
\hline O/ANY & $\circ / 0 \varphi_{0}$ & $0 / 001$ & $0 / 001$ & I.YG/9VA & r०DHVQ/OM & DSIV/DVG & 10 & خطا \\
\hline$\circ \%$ & $\circ / 0$ & $\circ / \pi$ & $\circ / \mathrm{V}$ & $T / 1$ & $1 / 9$ & $1 / \Gamma$ & & ضريب تغييرات \\
\hline
\end{tabular}

اين بزّوهش بيشترين وزن هزار دانه r/VV گ كـرم و كمتـرين وزن هزار دانه צس/ץ گرم در تيمارهاى سهبار آبيارى و تيمار ديم بود. در عملكرد روغن مقايسة تكىآبيارى كلزا در r مرحلة كلدهى و

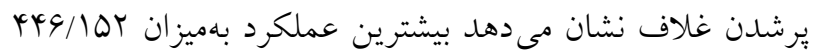

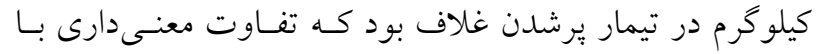
تيمار كلدهى نداشت. رائو و مندهام (TY) با بررسى اثر سـطوح

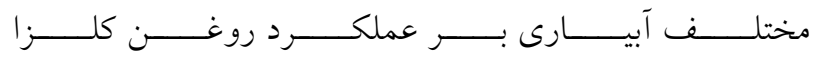
نشان دادند كه تــش در مراحـل زايشـى و انتهـايى رشـــ كلـزا سـبب كـاهش عملكــرد روغـن دانـهـ كلـزا مسى شــود. اعمــال آبيارى تكميلى، درصد روغن دانسه كلـزا را بـهـــور معنسى دارى افزايش داد. بهطورىكه اعمال دو و سه بار آبيارى درصد روغن

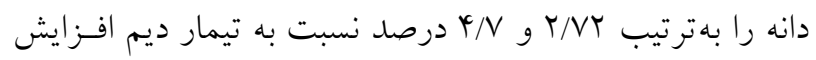
داد. همجنين نتايج نشان داد كـه تيمـار دو بـار آبيـارى و تيمـار تكىآبيارى در مرحلة يرشدن غلاف r درصد با هم اخـتلاف در

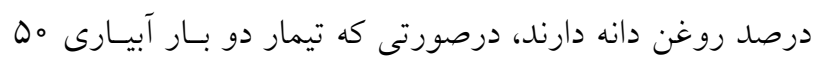

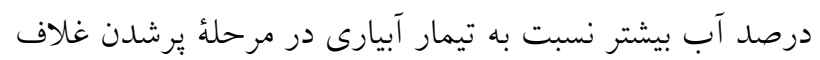
در طول اعمال تيمار دريافت كرده است. اين امر با نتايج تحقيق ديخر مبنى بر كاهش توليد روغن دانه كلزا در شرايط كمبود آب در مراحل حساس رشــ خصوصـاً مرحلـهُ يـر شـدن غـلاف و كلدهى مطابقت دارد (Yq). بين تيمارهاى تـكآبيـارى، تفـاوت طول غلاف معنى دار نشد، كه اين به معناى كفايست تـكآبيـارى در يكى از مراحل حساس كلدهى يـا يـر شـــن غـلاف اسـت.

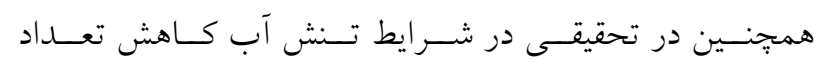

(جدول ه). بر اين اساس مقايسهُ ميانخين صفات مـورد بررسى با استفاده از آزمون دانكن انجام شد و نتايج آن در شكل بإئ ارائه شد. همان كونه كـه در شـكل مشـــص اسـت بيشـترين مقــار صفات مختلف در تيمار ب بار آبيارى حاصل شد بـهــورى كـه ميزان عملكرد دانه، عملكرد بيولوزيكى و عملكرد روغن در ايسن

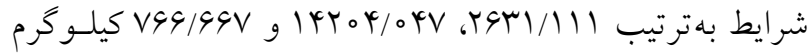
در هكتار بهدست آمل و با ساير تيمارهـا در سـطح آمـارى يـى درصد تفـاوت معنسى دارى نشـان داد. از طـرف ديخــ كمتـرين مقادير صفات مورد بررسى در تيمار بدون آبيارى (ديم) بهدست آمد. در شرايط ديم عملكرد دانه، عملكرد بيولوزيك و عملكـــد

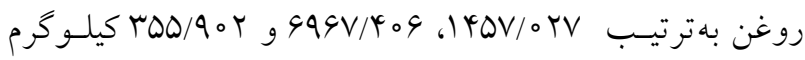
در هكتار بودند كه نسبت بـه شـرايط سـهبـار آبيـارى بـهميـزان

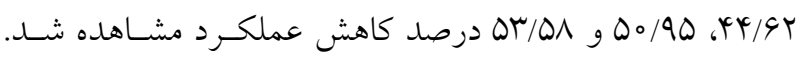

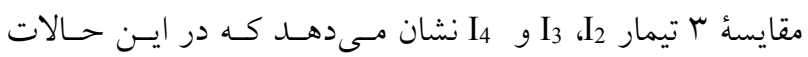
بيشترين عملكرد دانه، عملكرد بيولوزيك و عملكـرد روغـن در

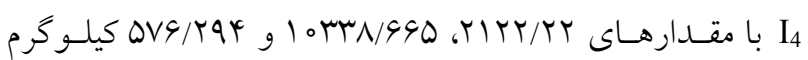
در هكتار بهدست آمد و با تيمارهاى تكآبيـارى تفـاوت معنىى دارى داشت. براى ارتفاع بوته و وزن هزار دانه نيز بين تيمار سه بار آبيارى، تيمار ديم و تيمارهاى آبيارى تكميلى تفـاوت معنى دار بود. بيشترين ارتفاع بوته 1/1/ متر و كمتـرين اس// متـر در تيمارهاى سهبار آبيارى و ديــم بــود. نـورى و همكــاران (19) و توحيدى و همكاران (Tr) در بررسىهاى خود نشان دادند بـين تعداد آبيارى و ارتفاع بوته همبستخى معنىدارى وجود دارد. در 


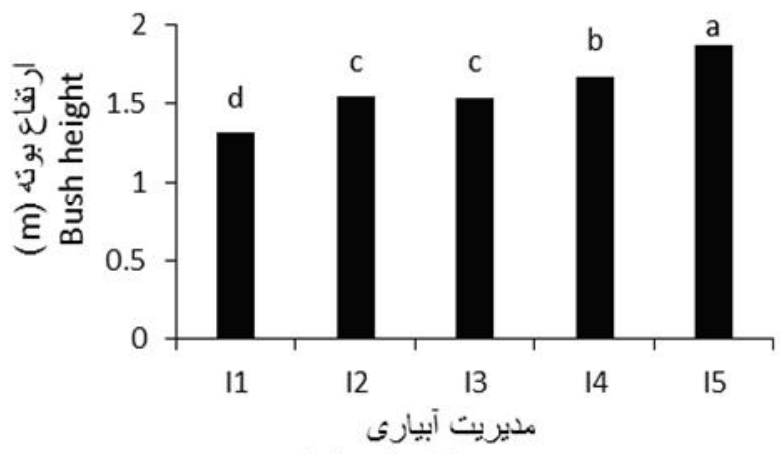

Irrigation Management

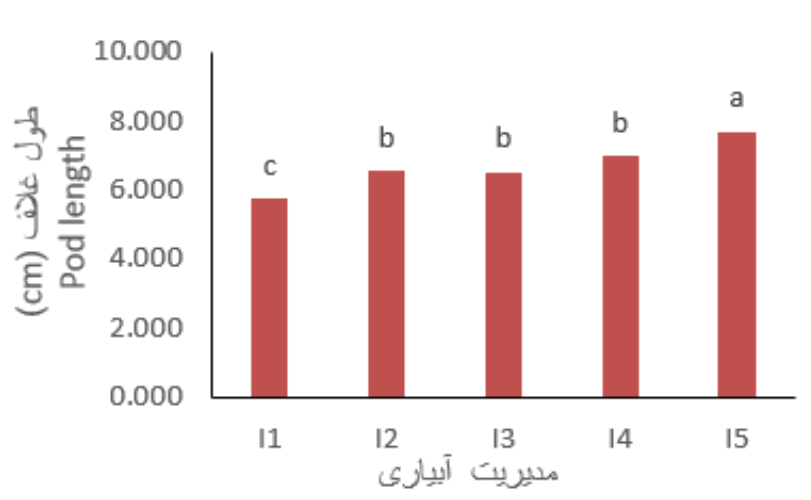

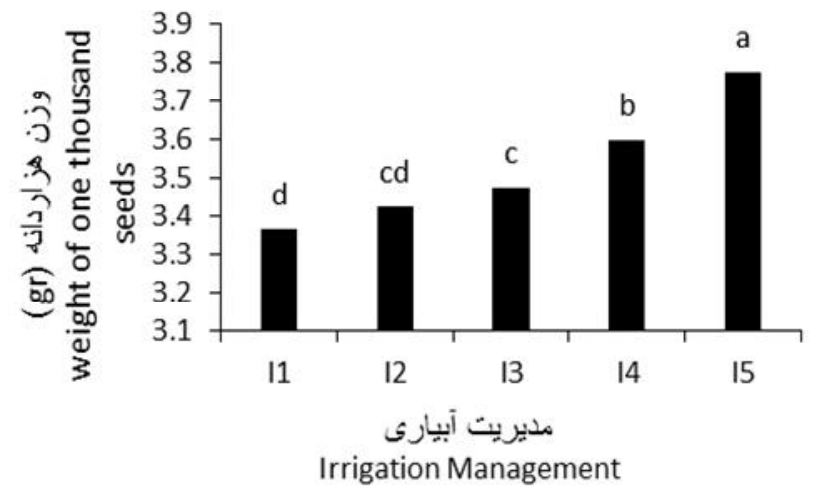
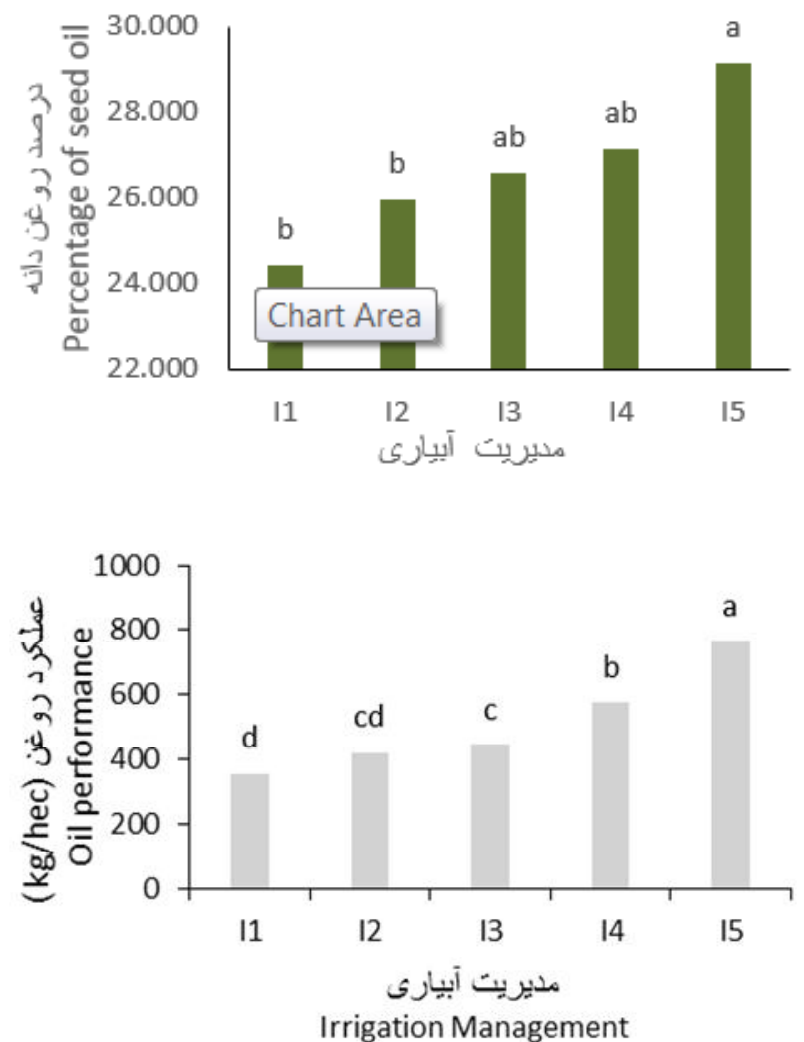

Irrigation Management

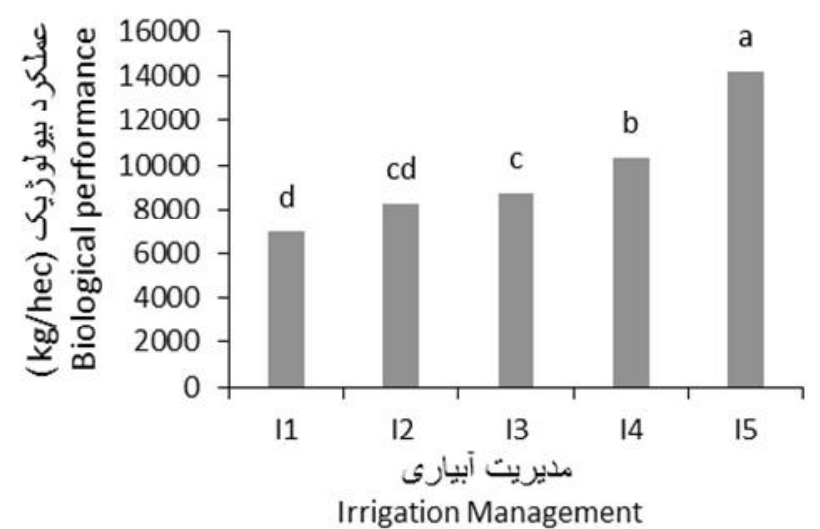

شكل r. تأثير آبيارىهاى مختلف بر صفات مختلف كلزا 
جدول 9. تجزيه واريانس تأثير تيمارهاى آبيارى بر بهرهورى آب كلزا

\begin{tabular}{|c|c|c|c|c|c|c|c|}
\hline & \multicolumn{5}{|c|}{ ميانخين مربعات } & \multirow{2}{*}{ درجه آزادى } & \multirow[t]{3}{*}{ منابع تغييرات } \\
\hline بهرهورى كل & بهره ورى كل & بهرمورى باران & بهرهورى باران & بهرهورى آبيارى & بهرهورى آبيارى & & \\
\hline (عملكرد روغن) & (عملكرد دانه) & (عملكرد روغن) & (عملكرد دانه) & (عملكرد روغن) & (عملكرد دانه) & & \\
\hline$\circ / 001^{* *}$ & $\circ / \circ \circ D^{* *}$ & $\circ / 001^{* *}$ & $\circ / \circ \circ V^{* *}$ & $1 / \circ \Delta \Delta^{* *}$ & $1 \% / 900^{* * *}$ & $r$ & تيمار \\
\hline$\circ / 000$ & $0 / 000$ & $\circ / 000$ & $\circ / 000$ & O/O० & $\circ / 0 \circ Y$ & 10 & خطا \\
\hline$r \circ / g r$ & $0 / 09$ & $19 / 91$ & $0 / Y q$ & $1 / 09$ & $0 / 91$ & & ضريب تغييرات \\
\hline
\end{tabular}

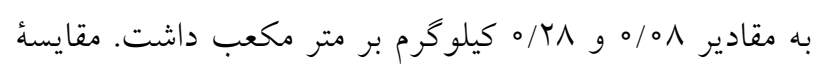

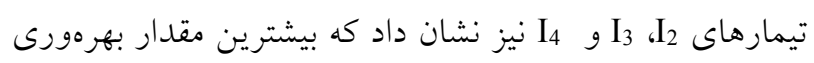
باران براى عملكرد دانه و عملكرد روغن را تيمار I4 داشـت و با تيمارهاى تكىآبيارى تفاوت معنى دارى داشت. مقايسهُ تـأثير

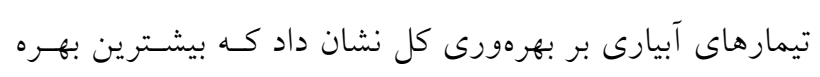

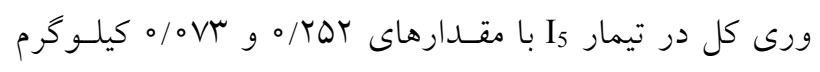
بر متر مكعب بهترتيب نسبت به عملكرد دانه و روغن بهدست

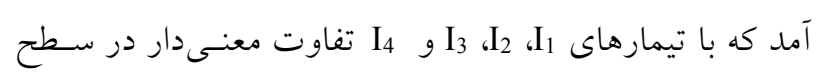
احتمال يك درصد داشت. از سوى ديخر كمترين بهرهورى كل

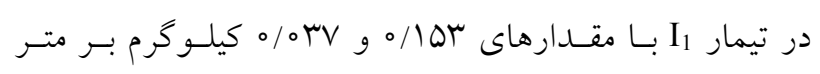
ت

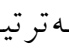
مكe به عملكرد دانه و روغن بهدست آمد كـه نسـبت بـه تيمـار

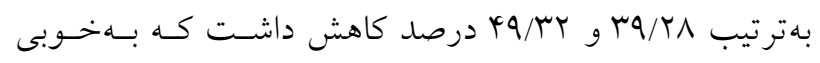

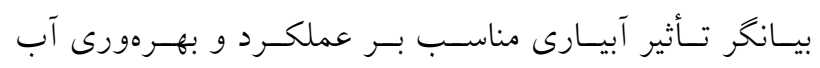

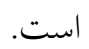

\section{نتيجه كيرى}

مطابق با نتايج اين يـرزوهش بـراى ارزيـابى تيمـارهـاى آبيـارى

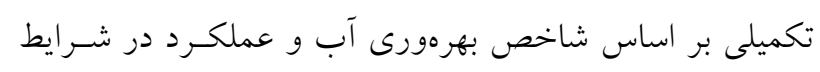

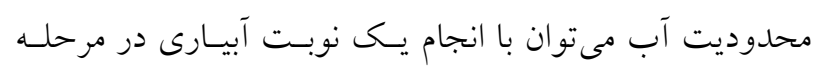

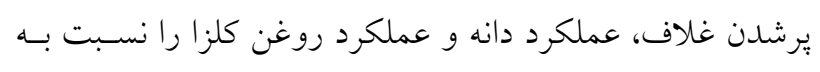

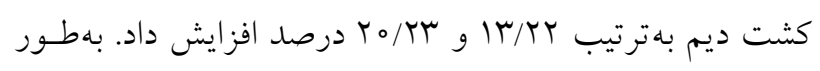

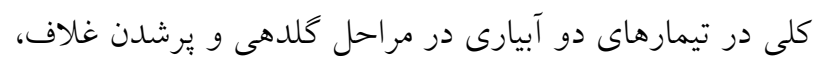

غلاف در بوته، تعداد دانه در غلاف و طول غلاف گزارش شده

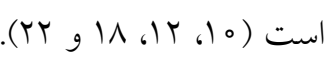
بهطور كلى بررسى تيمارهاى مختلف آبيارى نشان مسىدهـد

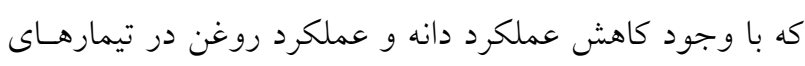
تكىآبيارى نسبت به تيمار ب بـار آبيـارى در شــايط كمبـود آب

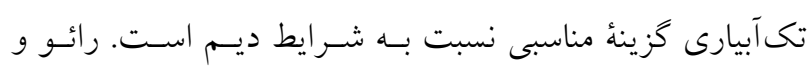
مندهام (YY) نيز در مطالعه خود ملاحظه كردند كـه يـك نوبـت آبيارى براى افزايش عملكــــ كفايـت نمسىكنـد، آنهـا مشـاهده كردند كه با يكى نوبت آبيارى در زمان كلـدهى تغييسر عملكـرد ناجيز بود، ولى با سه نوبت آبيارى تعداد غلاف و تعداد دانه در غلاف افزايش يافت.

نتايج تجزيه واريانس مديريتهاى مختلـف آبيـارى نشـان

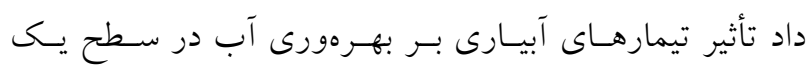

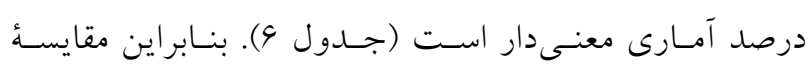

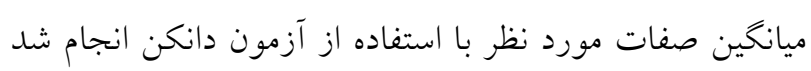

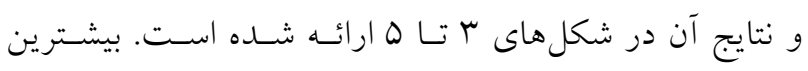
مقدار بهرهورى آب آبيارى براى عملكرد دانه و عملكرد روغن در تيمار I3 حاصل شد به طورى كه در اين شـر ايط بـهـترتيـب

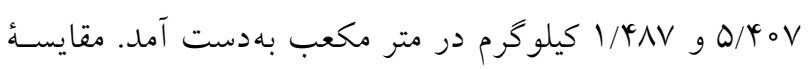

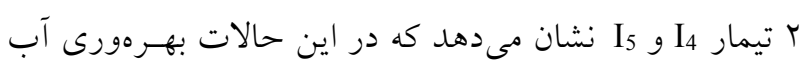
آبيارى براى عملكرد دانـه تفـاوت معنسى دارى داشــت. نتـايج مقايسٔ ميانخين بهرهورى باران نشان داد كه بيشترين بهرهورى بهري باران براى عملكرد روغن و عملكرد دانه را تيمار I5 بهترتيـب لهري 


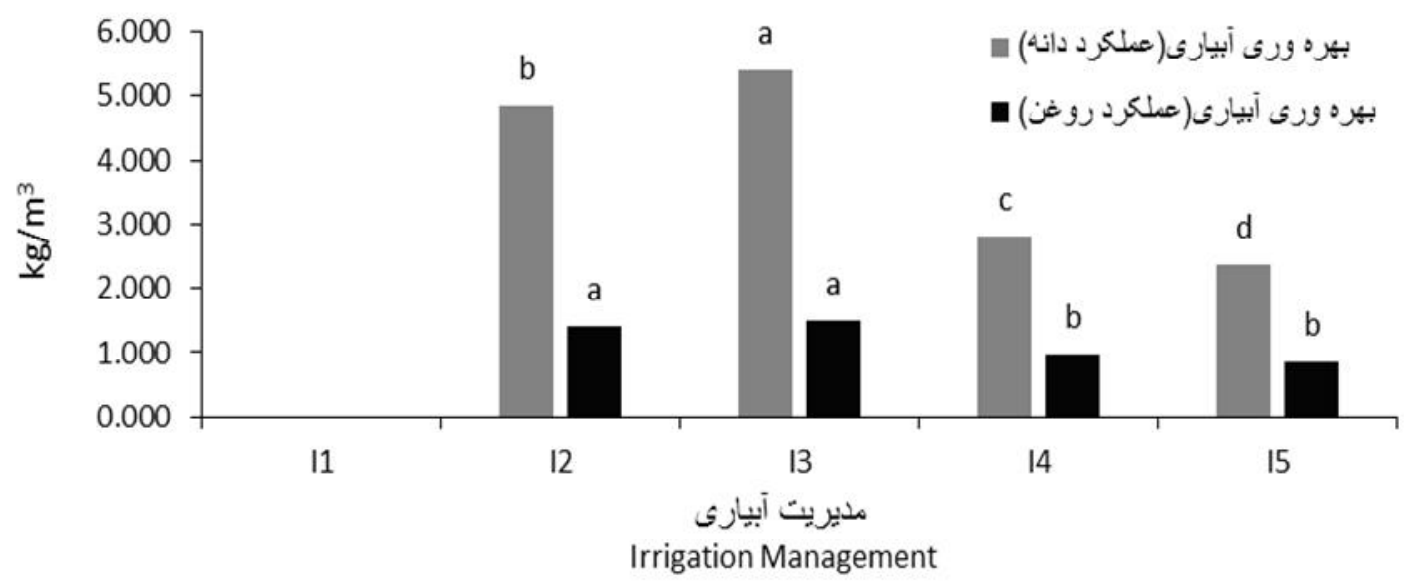

شكل r. تأثير مديريتهاى مختلف آبيارى بر بهرهورى آب آبيارى در كشت كلزا

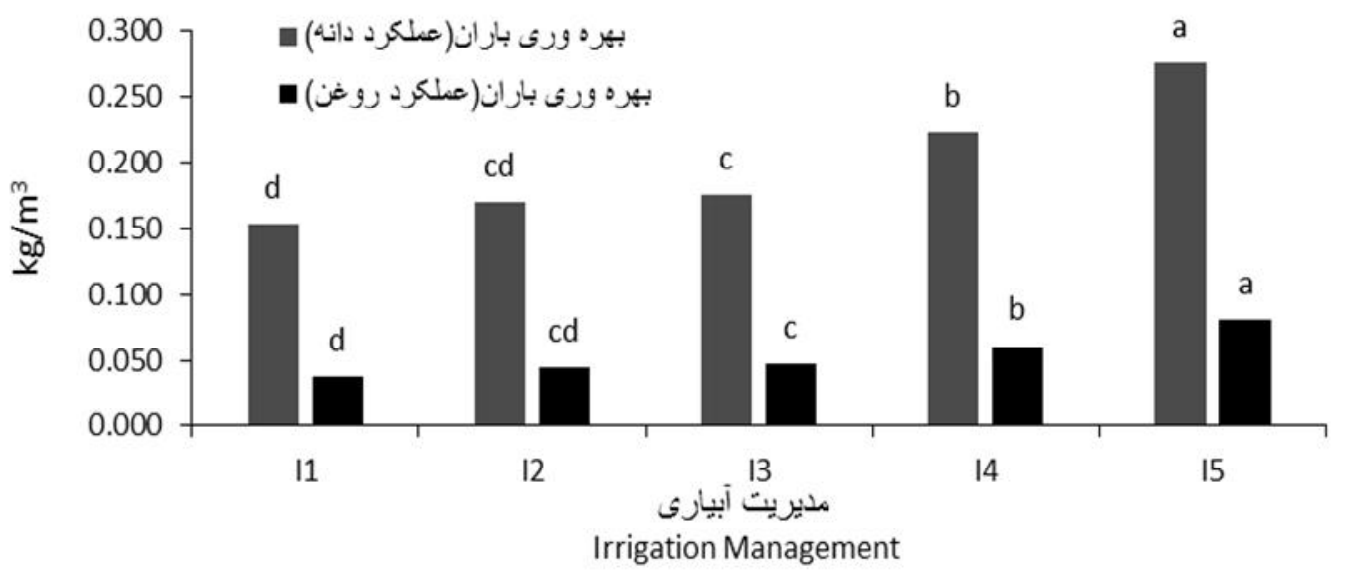

شكل Y. تأثير مديريتهاى مختلف آبيارى بر بهرهورى آب باران در كشت كلزا

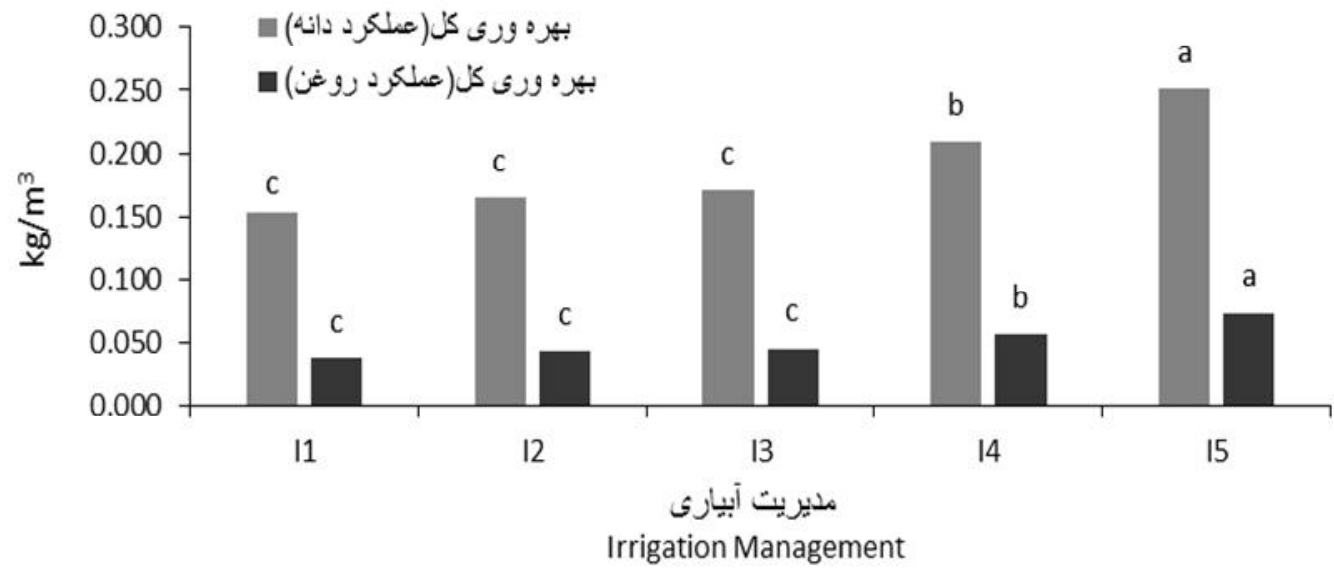

شكل ه. تأثير مديريتهاى مختلف آبيارى بر بهرهورى آب كل (آبيارى+باران) در كشت كلزا 


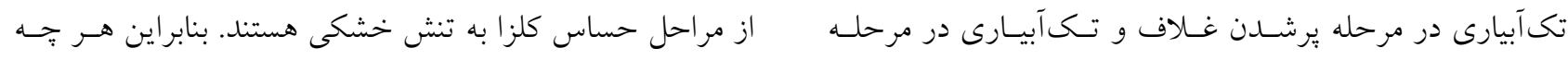

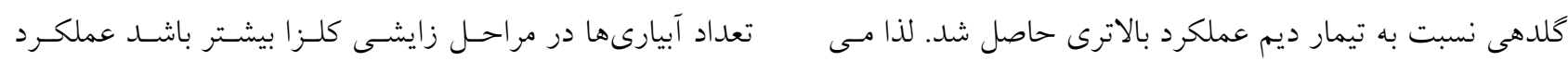

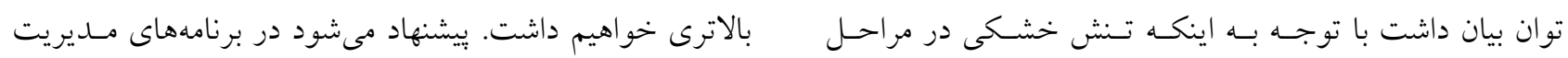

$$
\begin{aligned}
& \text { زايشى كلزا موجب كاهش عملكرد مىشود، درنتيجه اين مراحل آبيارى به اين شاخصها توجه بيشترى شود. }
\end{aligned}
$$

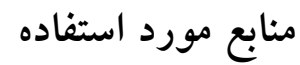

1. Abbasian, A. and A. H. Shirani Rad. 2011. Investigation of the response of rapeseed cultivars to moisture regimes in different growth stages. Journal of Central European Agriculture 12(2): 353-366.

2. Abedi, T. and H. Pakniyat. 2010. Antioxidant enzyme changes in response to drought stress in ten cultivars of oilseed rape (Brassica napus L.). Czech Journal of Genetics and Plant Breeding 46(1): 27-34.

3. Camaş, N., C. Cirak and E. Esendal. 2007. Seed yield, oil content and fatty acids composition of safflower (Carthamus tinctorius L.) grown in northern Turkey conditions. Journal of the Faculty of Agriculture. OMU 22: 98104.

4. Canakci. M., I. Topakci, I. Akinci and A. Ozmerzi. 2005. Energy partner of some field crops and vegetable production: case study for Antalya. Energy Conversion and Management 46(4): 655-666.

5. Clarke, J. and G. C. Simpson. 1978. Influence of irrigation and seeding rates on yield and yield components of Brassica napus. Canadian Journal of Plant Science 58: 731-737.

6. Dehshiri, A., M. Ahmadi and Z. Tahmaseb Servestani. 2001. Response of rapeseed cultivars to water stress. Journal of Agricultural Sciences 32(3): 649-659. (In Farsi).

7. Dogan, E., O. Copur, A. Kahraman, H. Kirnak and M. E. Guldur. 2011. Supplemental irrigation effect on canola yield components under semiarid climatic conditions. Agricultural Water Management 98(9): 1403-1408.

8. Eskandari, H. and A. Alizadeh Amraie. 2016. The effect of supplementary irrigation at the reproductive growth stage on grain yield, oil and energy efficiency of canola production system in dryland conditions. Journal of Crop Improvement 18(4): 907-919.

9. Hasanzadeh, M., A. H. Shirani Rad, M. R. Naderi Darbaghshahi, F. Majd Nasiri and H. Madani. 2005. Effect of drought stress on yield and yield components of autumn high rape cultivars. Journal of Agriculture 7(2): 17-24. (In Farsi).

10. Heidarpour, N. and S. Talaie. 2016. Effect of supplementary irrigation and nitrogen on wheat yield and agronomic traits (Triticum aestivum L.) dry cultivar of Koohdasht. Iranian Crop Sciences 47(4): 541-549. (In Farsi).

11. Hoseini, F., A. Nezami, M. Parsa and K. Haj Mohmad Nia Ghalibaf. 2016. Effect of supplemental irrigation in phenological stages on some growth indices of lentil cultivars in Mashhad. Iranian Journal Pulses Research 7(1): 105-120. (In Farsi).

12. Ismail, S. M. 2016. Maximizing production and irrigation water productivity of canola crop (Brassica napus L.) under arid land conditions. Irrigation and Drainage 65(3): 254-263.

13. Jamshidi, N., A. H. Shirani Rad, F. Takht Chin, P. Nazeri and M. Ghafari. 2012. Evaluation of rapeseed cultivars under drought stress conditions. Journal of Crop Ecophysiology 323-338. (In Farsi).

14. Jensen, C. R., R. O. Mogensen, G. Mortensen, J. K. fieldsend, G. F. J. Milford, M. N. Andersen and J. H. Thaga. 1996. Seed glucosinolate, oil and protein contents of field grown rape (Brassica napus L.) as affected by soil drying and evaporative demand. Field Crops Research 47: 93-105.

15. Johnston, A. M., D. L. Tanaka, P. R. Miller, S. A. Brandt, D. C. Nielsen, G. P. Lafond and N. R. Riveland. 2002. Oilseed crops for semiarid cropping systems in the Northern Great Plains. Agronomy Journal 94: 231-240.

16. Kimber, D. S. and D. L. Gregor. 1995. Brassica oil seed: Production and utilization. CAB international. Region, Turkey. Energy Conservation and Management 46: 655-666.

17. Koocheki, A., S. M. Seyyedi and M. Jamshid Eyni. 2014. Irrigation levels and dense planting affect flower yield and phosphorus concentration of saffron corms under semi-arid region of Mashhad. Northeast. Scientia Horticulturae 180: $147-155$.

18. Mostafavi Rad, M., M. Azad Marzabadi and S. Faraji. 2013. Evaluation of seed traits and qualitative function in some winter rapeseed cultivars. Journal of Applied Crop Breeding 33-42. (In Farsi).

19. Noori, S. A., H. Khalaj, A. H. Rad, I. Alahdadi, G. A. Akbari and M. R. Abadi. 2007. Investigation of seed vigor and germination of canola cultivars under less irrigation in padding stage and after it. Pakestan Journal Biology Science 10(17): 2880-2884. 
20. Oad. F. C., B. K. Solangi, M. A. Samo, A. A. Lakho, Z. Ul-Hassan and N. L. Oad. 2001. Growth, yield and relationship of rapeseed (Brassica napus L.) under different row spacing. International Journal of Agriculture and Biology 3: 475-476.

21. Oweis, T., A. Hachum and J. Kijne. 1999. Water harvesting and supplementary irrigation for improved water use efficiency in dry areas. System-Wide Initiative on Water Management Paper 7. Colombo, Sri Lanka: International Water Management Institute.

22. Rad, A. H. S., A. Abbasian and H. Aminpanah. 2014. Seed and oil yields of rapeseed (Brassica napus L.) cultivars under irrigated and non-irrigated conditions. The Journal of Animal \& Plant Sciences 24(1): 204-210.

23. Rao, G. and N. J. Mendham. 1991b. Comparison of Chinoli (B. campestris) and B. napus oilseed rape using different growth regulators, plant population densities and irrigation treatments. Journal of Agricultural Science (Cambridge) 117: 177-187.

24. Rao, M. S and N. J. Mandham. 1991a. Soil plant-water relations of oilseed rape (B. napus, B. compestris). Journal. Agriculture Science Combridge 117: 197-205.

25. Rezaei-Chiyaneh, E., S. M. Seyyedi, E. Ebrahimian, S. Siavash Moghaddam and C. A. Damalas. 2018. Exogenous application of gamma-aminobutyric acid (GABA) alleviates the effect of water deficit stress in black cumin (Nigella sativa L.). Industrial Crops and Products 112: 741-748.

26. Robertson, M. J. and J. F. Holland. 2004. Production risk of canola in the semi-arid subtropics of Australia. Australian Journal of Agricultural Research 55: 525-538.

27. Sayari, N., M. Bannayan, A. Alizadeh and A. Farid. 2013. Using drought indices to assess climate change impacts on drought conditions in the northeast of Iran (case study: Kashafrood basin). Journal of Applied Meteorology and Climatology 20: 115-127.

28. Shabani, A., A. Kamkar Haghighi, A. Sepaskhah, Y. Emam and T. Honar. 2019. Effect of water stress on seed yield, yield components and quality of autumn canola lycord cultivar. Iranian Journal of Crop Sciences 409-421. (In Farsi).

29. Shirani Rad, A. H. 2012. Winter rapeseed response to zeolite and nitrogen rates under different irrigation regimes. International Journal of Advanced Science and Technology 2(1): 108-115.

30. Tavakkoli, A. R. and T. Y. Owise. 2002. The role of supplemental irrigation and nitrogen in producing bread wheat in the highlands of Iran. Agriculture Water Management 65: 225-236.

31. Tavakoli, A. and B. Abdolrahmani. 2015. Effect of single irrigation on seed yield and agronomic traits of spring rapeseed under rainfed conditions. Journal of Agriculture 106: 64-72. (In Farsi).

32. Tohidi-M, H. R., A. H. Shirani-Rad, G. Nour-Mohammadi, D. Habibi, S. A. M. Modarres-anavy, M. MashhadiAkbar-Boojar and A. Dolatabadian, A. 2009. Response of six oil seed rape genotype to water stress and hydrogical application. Pesquisa Agropecuária Tropical. Trop., Goiânia 3: 243-250.

33. Younesi, O., and A. Moradi. 2009. The effect of water limitation in the field on sorghum seed germination and vigor. Australian Journal of Basic and Applied Sciences 3(2): 1156-1159. 


\title{
Effect of Supplementary Irrigation at Different Growth Stages on the Yield and Water Productivity of Autumn Rapeseed Cultivar Rohan (Khorramabad)
}

\author{
F. Alizadeh, A. H. Nasrollahi', M. Saeedinia and M. Sharifipour ${ }^{1}$
}

(Received: January 18-2020; Accepted: July 1-2020)

\begin{abstract}
In areas with high rainfall distribution, proper irrigation management, including complementary irrigation, is one of the effective strategies to increase crop production. In order to investigate the effect of supplementary irrigation in different growth stages on the yield and water productivity of Autumn rapeseed, an experiment in the form of a complete randomized block design with five irrigation management treatments including rainfed (I1), single irrigation at flowering stage (I2), single Irrigation at pod filling stage (I3), two irrigation at pod filling stage and flowering (I4), three irrigation at flowering, and pod filling and grain Filling stages (I5) was carried out at Lorestan University Research Field. Results showed that there was a significant difference between the effects of different irrigation treatments at $1 \%$ level. The lowest grain yield, biological yield and oil yield were obtained in I1 treatment with $44.62 \%, 50.95 \%$ and $53.58 \%$ decrease, as compared to I5 treatment. The results also showed that by applying irrigation at pod filling stage, grain yield and oil yield were increased by $13.22 \%$ and $20.23 \%$, as compared to I1 treatment. The highest total productivity for the grain yield and oil yield was obtained in 15 treatment with 0.252 and $0.073 \mathrm{~kg} / \mathrm{m} 3$. In general, due to the fact that drought stress in rapeseed calving stages reduces yield, the higher the number of irrigations in rapeseed calving stages, the more the yield.
\end{abstract}

Keywords: Single irrigation, Oil yield, Biological yield, Water stress

1. Irrigation and Drainage Department, College of Agriculture and Natural Resources, Lorestan University, Lorestan, Iran.

Corresponding author, Email: nasrolahi.a@lu.ac.ir 